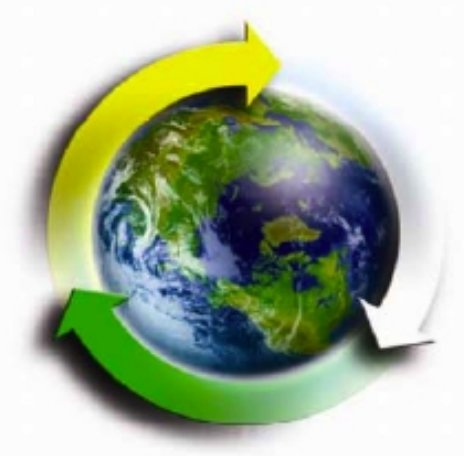

Definition of Technology Readiness Levels For Transmutation Fuel Development

Global Nuclear Energy Partnership

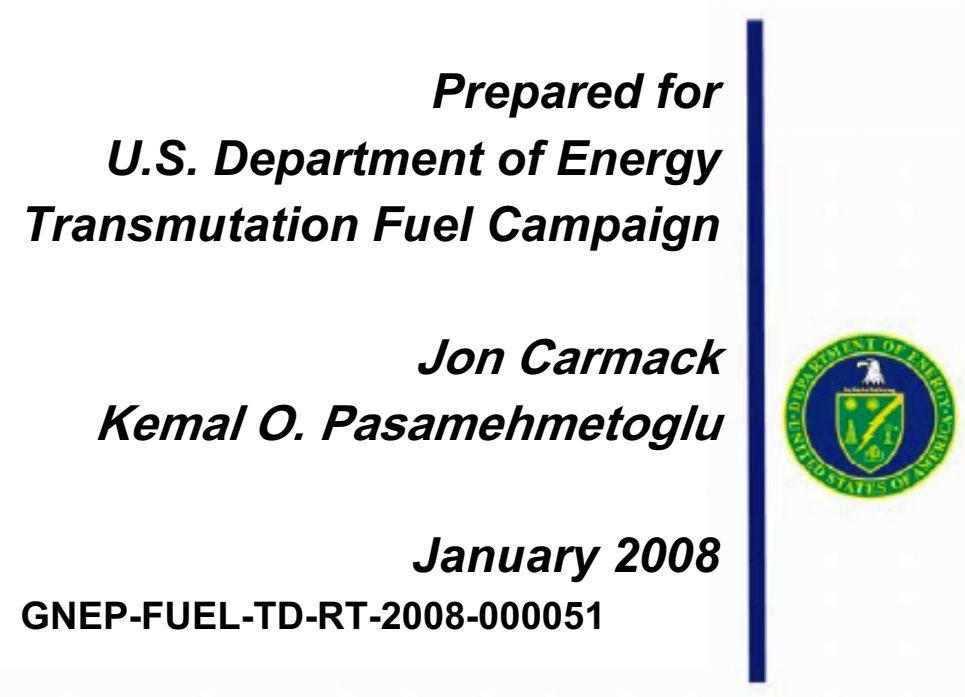




\title{
Definition of Technology Readiness Levels for Transmutation Fuel Development
}

\author{
Jon Carmack \\ Kemal O. Pasamehmetoglu
}

January 2008

Idaho National Laboratory

Idaho Falls, Idaho 83415

Prepared for the

U.S. Department of Energy

Office of Nuclear Energy

Under DOE Idaho Operations Office

Contract DE-AC07-05ID14517 


\section{DISCLAIMER}

This information was prepared as an account of work sponsored by an agency of the U.S. Government. Neither the U.S. Government nor any agency thereof, nor any of their employees, makes any warranty, expressed or implied, or assumes any legal liability or responsibility for the accuracy, completeness, or usefulness, of any information, apparatus, product, or process disclosed, or represents that its use would not infringe privately owned rights. References herein to any specific commercial product, process, or service by trade name, trade mark, manufacturer, or otherwise, does not necessarily constitute or imply its endorsement, recommendation, or favoring by the U.S. Government or any agency thereof. The views and opinions of authors expressed herein do not necessarily state or reflect those of the U.S. Government or any agency thereof. 
Reviewed by:

Director, Transmutation Fuel Campaign

Transmutation Fuel Campaign Director

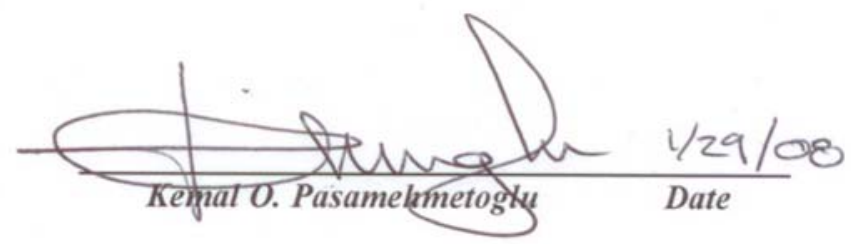

Deputy Director, Transmutation Fuel

Campaign

Transmutation Fuel Campaign Deputy Director

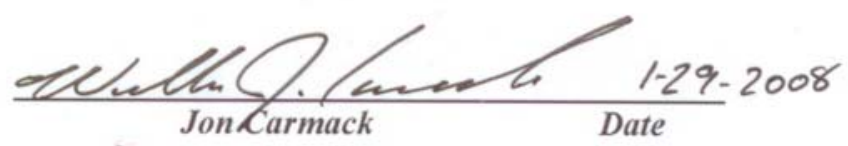


INTENTIONALLY BLANK 


\section{SUMMARY}

To quantitatively assess the maturity of a given technology, the Technology Readiness Level (TRL) process is used. The TRL process has been developed and successfully used by the Department of Defense (DOD) for development and deployment of new technology and systems for defense applications. In addition, NASA has also successfully used the TRL process to develop and deploy new systems for space applications.

Transmutation fuel development is a critical technology needed for closing the nuclear fuel cycle. Because the deployment of a new nuclear fuel forms requires a lengthy and expensive research, development, and demonstration program, applying the TRL concept to the transmutation fuel development program is very useful as a management and tracking tool. This report provides definition of the technology readiness level assessment process as defined for use in assessing nuclear fuel technology development for the Transuranic Fuel Development Campaign. 
INTENTIONALLY BLANK 


\section{CONTENTS}

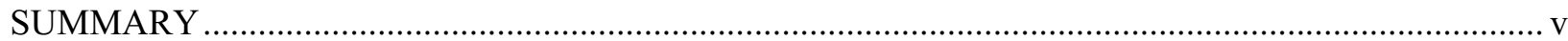

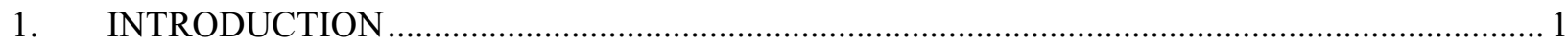

2. FUEL REQUIREMENTS AND SELECTION CONSIDERATIONS …................................... 1

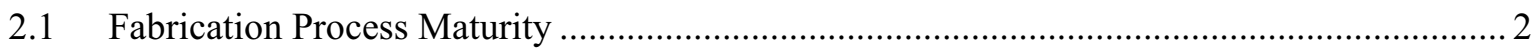

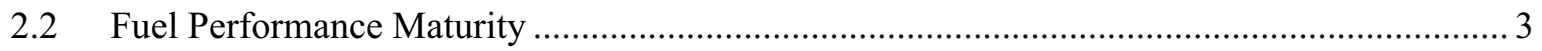

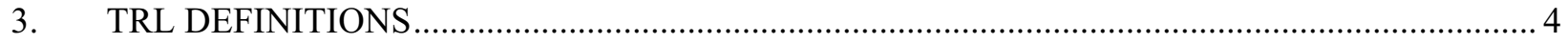

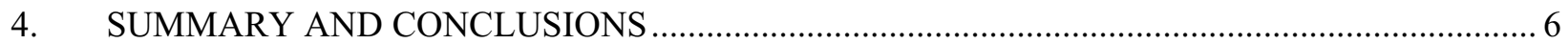

\section{FIGURES}

Figure 1. Summary of TRL evaluation elements, attributes, and bins.................................................. 2

\section{TABLES}

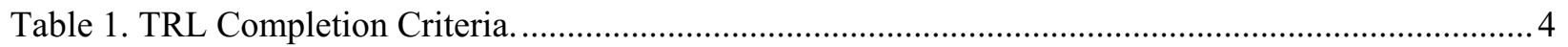

Table 2. TRL Binning for Fabrication Process Maturity...................................................................... 5

Table 3. TRL Binning for Irradiation Performance Maturity. ............................................................... 5

Table 4. Summary of TRL Definition for Transmutation Fuels. ............................................................ 6 
INTENTIONALLY BLANK 


\section{DEFINITION OF TECHNOLOGY READINESS LEVELS FOR TRANSMUTATION FUEL DEVELOPMENT}

\section{INTRODUCTION}

In order to provide a quantitative assessment for the maturity of a given system relative to its full-scale deployment, a technology readiness level (TRL) process is developed and used by the Department of Defense (DoD). Subsequently, the National Aeronautics and Space Administration (NASA) also successfully used the TRL process to develop and deploy new systems.

Transmutation fuel development is a critical part of the Advanced Fuel Cycle Initiative (AFCI) program aimed at developing advanced technologies for closing the nuclear fuel cycle. Because the deployment of a new fuel form requires a lengthy and expensive research, development, and demonstration program, applying the TRL concept to the transmutation fuel development program is very useful as a management and tracking tool.

In using TRL as an effective progress-tracking tool, the first step is to define quantitative definitions with specific criteria for different TRLs. The attributes to defining the quantitative definitions specifically for transmutation fuels are discussed in the following section.

\section{FUEL REQUIREMENTS AND SELECTION CONSIDERATIONS}

There are two elements to assessing the maturity of a new fuel type in terms of readiness for deployment:

A. Fabrication Process Maturity, which measures how well the fabrication process is understood and validated; and

B. Fuel Performance Maturity, which measures how well the in-pile performance of the fuel is understood and validated.

A TRL definition that provides a balance between these two elements is essential. Having a very mature fabrication process tested at very large scales for fuels with large uncertainties in its performance certainly does not make sense. On the other hand, collecting a lot of performance data through large-scale testing without a mature definition of the fabrication process is equally unbalanced. As shown in Figure 1, for each element, there are two attributes identified for assessing the TRL levels. Figure 1 also shows, for each attribute, the distinct bins against which the state-of-knowledge can be compared. The attributes and the bins summarized in Figure 1 are discussed in detail in the following subsection. 


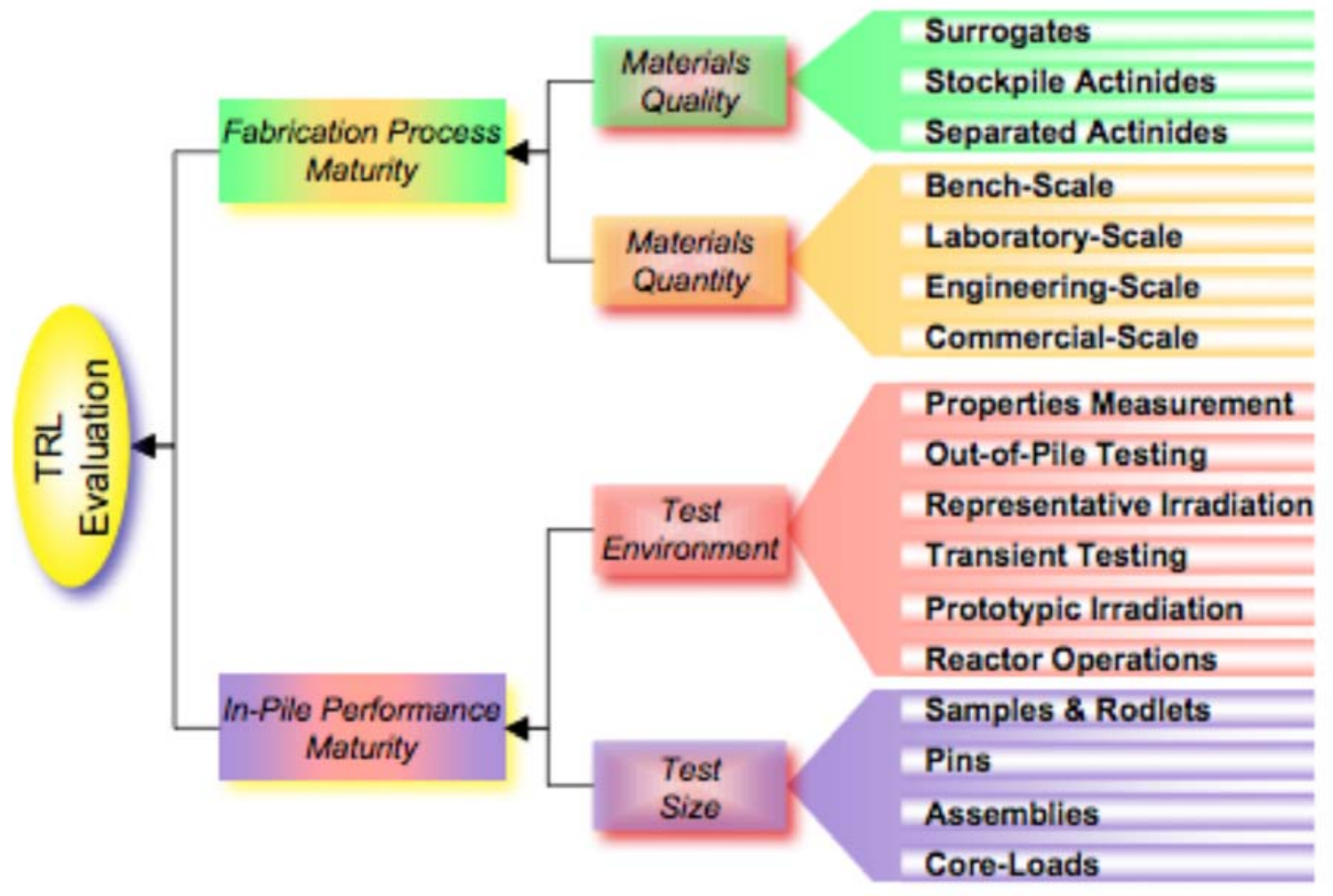

Figure 1. Summary of TRL evaluation elements, attributes, and bins.

\subsection{Fabrication Process Maturity}

To gauge the maturity of the fabrication process, there are two important attributes that must be considered:

1. Quality of Materials Used For Fabrication Process Development and Testing. This attribute is broken into three bins to gauge the TRL.

- Surrogate Materials - These are typically non-radioactive or less-radioactive materials with properties similar to the actual actinides. The selection of a surrogate depends on the specific phenomenon of interest and the properties that are important to predict or duplicate the phenomenon as closely as possible without using actual actinide materials.

- $\quad$ Representative Materials from Stockpile - These are individually separated actinide elements that must be blended together for use in fuel fabrication experiments. Quite often, the physical form of these materials is not prototypic of would be used as feedstock for fuel fabrication; thus, a non-prototypic conditioning step would be necessary. Also, the isotopic vectors for stockpile actinides are typically different than those obtained from the separation process using commercial spent nuclear fuel. Those differences must be accounted for in the fabrication testing as well.

- $\quad$ Representative Materials from Separations Process - Ultimately, the fabrication process must be optimized using actinides recovered from the separation processes, co-precipitated through a prototypic process, and conditioned to be used as feedstock. This phase of the development process requires a coordinated effort between the separations and fuel fabrication campaigns. 
2. Quantity of Materials Used for Fabrication Process Development and Testing. This parameter is broken into four categories to gauge the TRL. The quantity can be measured as batch size and/or throughput rate.

- $\quad$ Bench-Scale Fabrication - Dealing with gram quantities up to $100 \mathrm{~g}$ batch sizes (multiple pellets/slugs per year)

- $\quad$ Laboratory-Scale Fabrication - Dealing with kg quantity of batch-sizes with an equivalent throughput rate on the order of $10 \mathrm{~kg}$ TRU /year (multiple pins/year)

- Engineering-Scale Fabrication - Dealing with 1 - $10 \mathrm{~kg}$ quantity batch-sizes with an equivalent throughput rate on the order of $100 \mathrm{~kg}$ TRU /year (a few assemblies/year)

- Commercial-Scale Fabrication - Dealing with batch-sizes that are the same order of magnitude as the engineering-scale batch sizes but at a throughput rate on the order of tons of TRU/year (a few hundred assemblies per year - core loads).

\subsection{Fuel Performance Maturity}

To gauge the maturity of fuel performance, there are two important parameters that must be considered:

1. Test Environment to Determine Performance Parameters. This parameter is broken into six categories to gauge the TRL.

- Fundamental Property Measurements - This category includes measurements of basic mechanical, thermal, and chemical properties of samples that are fabricated through a representative process and that conform to defined specifications.

- $\quad$ Out-of-Pile Testing - This category includes experiments conducted without using reactor/neutron irradiations but that provide insight into the behavior of fuel and cladding. Examples of such tests include diffusion-couple experiments, microstructure evolution tests, ion-beam irradiation tests, thermal segregation experiments, etc.

- In-Pile Testing in Representative Spectrum - These are neutron irradiation experiments with fission where the spectrum and/or flux levels and/or thermal boundary conditions are not prototypic of fast reactors. Therefore, fuel design and enrichment levels may have to be adjusted to accommodate the non-prototypic nature of the irradiation environment. A good example is testing the fast reactor fuels using a thermal test reactor with or without partial filtering of thermal neutrons. Completion of the irradiation experiments implies that the associated post-irradiation examination (PIE) is performed.

- $\quad$ Transient Testing - This category includes transient tests to mimic fuel behavior during design basis accidents. The failure threshold determination also is covered under this category. Full size or partial size pins both before and after irradiation can be used in these tests. Irradiated pins may be those tested in representative or prototypic spectrum. Completion of the irradiation experiments implies that the associated PIE is performed.

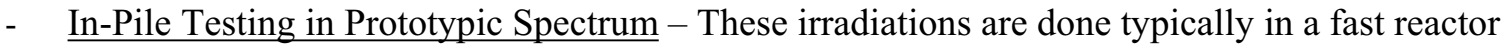
where flux, spectrum, and thermal effects are very similar to the actual reactor conditions for which the fuel is being qualified. Completion of the irradiation experiments implies that the associated PIE is performed.

- $\quad$ Reactor Operations - At this level, large quantities of fuel (that is already licensed) are used in actual reactor operations. Post-irradiation examination of selected pins may be performed to verify performance. 
2. Size of Test Campaigns to Assess Performance Parameters. This parameter is broken into four categories to gauge the TRL. In addition to size, the test geometry and the cladding used in the testing campaigns also are of importance for these categories.

- $\quad$ Samples \& Rodlets - These are samples (pellets, short slugs, etc.) testing in the form of rodlets (on the order of $10 \mathrm{~cm}$ fuel height). The testing may or may not include prototypic cladding and prototypic clad-coolant interactions. These tests are typically designed to look at specific issues/phenomena.

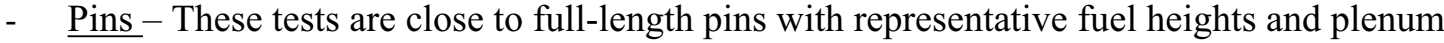
volumes. Prototypic clad materials are typically used in these tests.

- $\quad$ Assemblies - These tests contain assemblies of prototypic design. Lead test assemblies (LTAs) as well as limited number of assemblies used for partial core conversion are included in this category. Prototypic clad and assembly materials are used in these tests.

- Full-Core Assemblies - At this level, the irradiation is no longer a test program but an operations program where the statistical and long-term reliability related issues are quantified for the fuel type and design of interest.

\section{TRL DEFINITIONS}

Full maturity requires long-term routine operations of commercial fabrication plant(s) supplying fuels to operating reactors. At this point, adequate statistical data are available for fuel fabrication and performance, and the system is optimized within the constraints of the performance envelope. This level of maturity is assigned a numerical score of 9 for the corresponding TRL.

At the other end of the spectrum, when a new concept is proposed and it is shown that the concept is viable based on first principles assessment, a numerical score of 1 is assigned for the corresponding TRL.

The intermediate steps are defined based on the logical progression of the research and development towards demonstration and deployment, and the corresponding criteria are shown in Table 1 . The criteria in Table 1 determine the completion of the corresponding TRL level.

Table 1. TRL Completion Criteria.

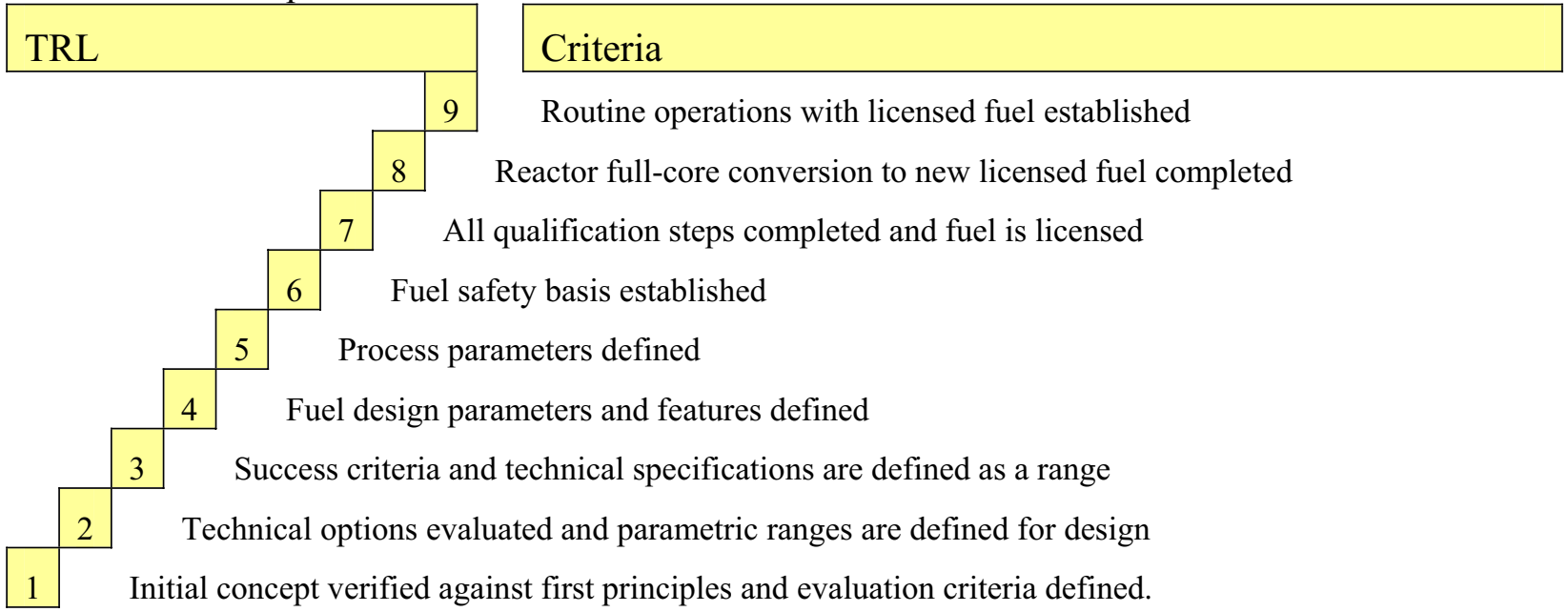

The process of evaluating the TRL is based on binning the state-of-knowledge for each attribute. Then, given the criteria, various activities required to achieve these goals are identified as a function of the technical elements, attributes, and bins (discussed in Section 2). The resulting TRLs are shown in Tables 2 and 3, for the fabrication and performance elements, respectively. 
Table 2. TRL Binning for Fabrication Process Maturity.

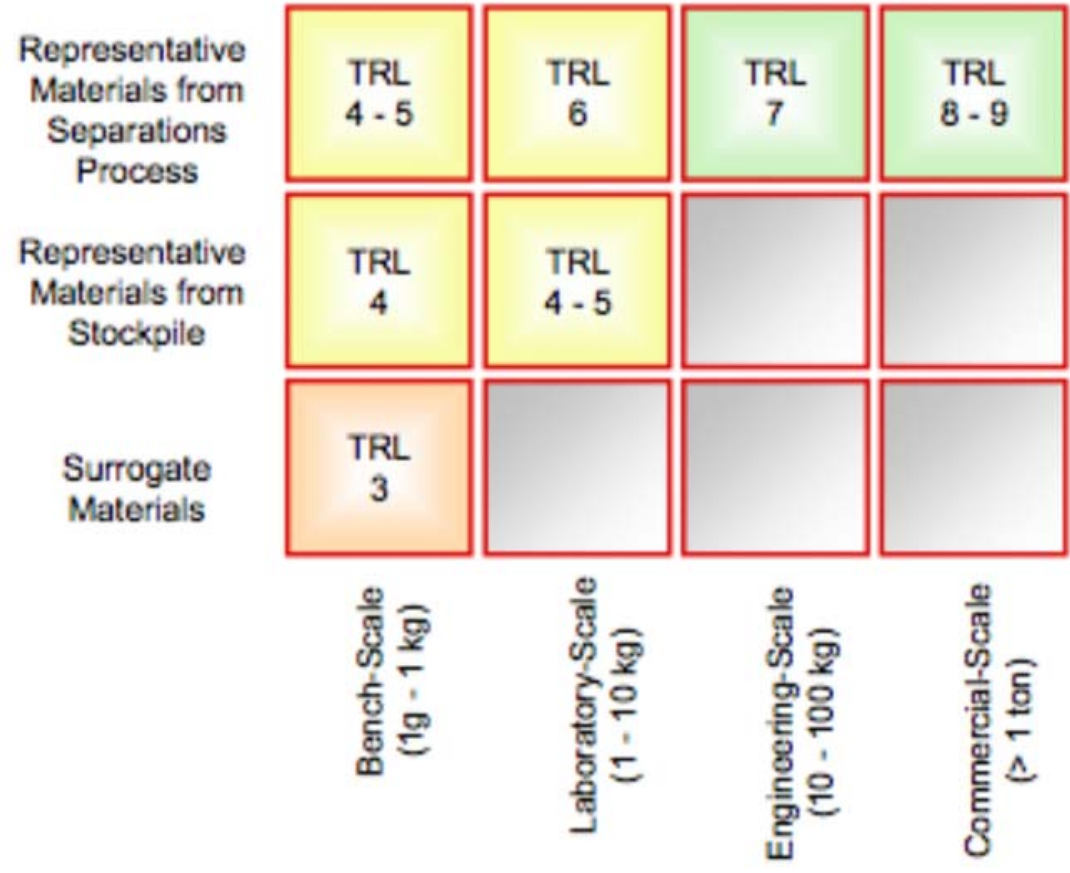

Table 3. TRL Binning for Irradiation Performance Maturity.

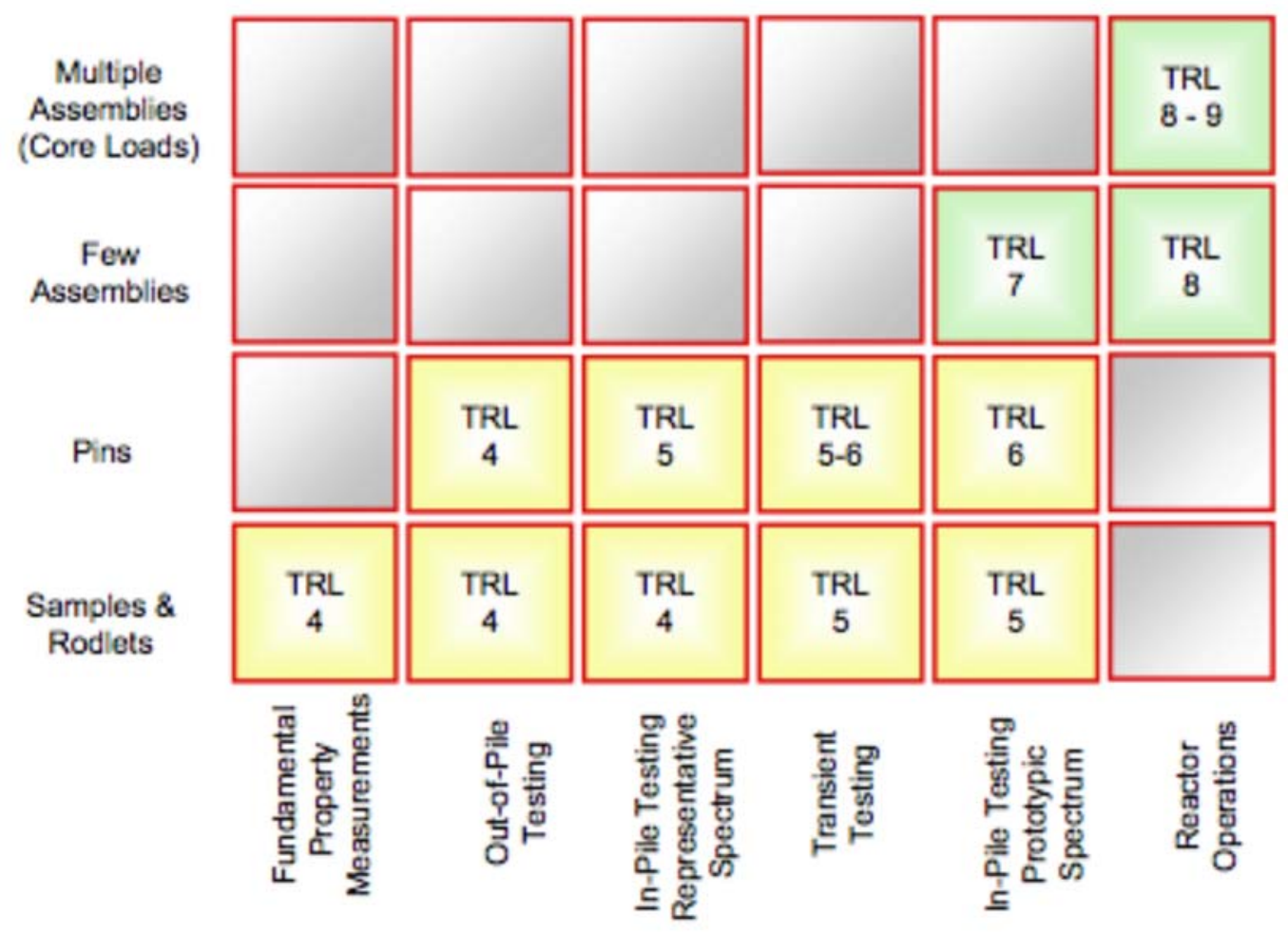




\section{SUMMARY AND CONCLUSIONS}

Table 4 summarizes the criteria and the activities needed to achieve the criteria for various TRL levels specific to transmutation fuel development. The definition of the TRL levels is based on a logical progression of the work, while considering fabrication and performance testing activities in tandem. All the activities in a given level must be completed before advancing to the next level.

TRL concept is used as a program management tool and is not meant as an absolute quantitative measure of maturity. There is naturally a level of subjectivity in defining and, also, in evaluating the TRLs. Nonetheless, with the granularity provided in the methodology outlined in this report, the technical maturity evaluations will provide a semi-quantitative, relative measure for the transmutation fuel technology, specifically, and to any new fuel concept, in general.

Finally, it is important to recognize the difference between the TRL evaluations and technical risk. The TRL only provides a relative measure of where the technology maturity is compared to the end objective of large-scale deployment. A low TRL does not necessarily mean a high technical risk. Technical risk depends on many factors (e.g., the complexity of the remaining work, the availability of the needed resources, schedule constraints) and must be evaluated independently.

Table 4. Summary of TRL Definition for Transmutation Fuels.

\begin{tabular}{|c|c|c|}
\hline TRL & Function & Definition \\
\hline 1 & & $\begin{array}{l}\text { - A new concept is proposed and appears feasible based on similar } \\
\text { systems/applications. } \\
\text { - Technical options for the concept are identified and relevant literature } \\
\text { data reviewed. } \\
\text { - CRITERION: Initial development plan and evaluation criteria are } \\
\text { developed. }\end{array}$ \\
\hline 2 & & $\begin{array}{l}\text { Technical options are ranked based on relevant available data (including } \\
\text { data from similar fuel types) and evaluation criteria. } \\
\text { - CRITERION: Performance range and fabrication process parametric } \\
\text { ranges are defined based on analyses, relevant available data (including } \\
\text { data from similar fuel types). }\end{array}$ \\
\hline 3 & 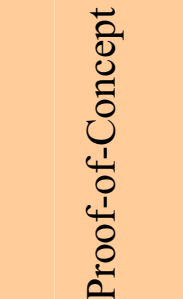 & $\begin{array}{l}\text { - Concepts are tested through bench-scale experiments and } \\
\text { characterization of fundamental properties. } \\
\text { - Fabrication process tested at bench-scale using surrogates. } \\
\text { - CRITERION: technical specifications are quantified as a range that } \\
\text { satisfies the success criteria. }\end{array}$ \\
\hline
\end{tabular}


Table 4. (continued).

\begin{tabular}{|c|c|c|}
\hline TRL & Function & Definition \\
\hline 4 & & $\begin{array}{l}\text { - Samples using stockpile materials are fabricated at bench-scale. } \\
\text { - Limited bench-scale fabrication with separated materials and } \\
\text { laboratory-scale fabrication with stockpile materials also are performed for } \\
\text { process evaluation only. } \\
\text { - Out-of-pile tests for important phenomena are conducted. } \\
\text { - Fundamental properties (with uncertainties) are measured and compiled. } \\
\text { - Irradiation testing of small-samples (rodlets) are performed in relevant } \\
\text { environment. } \\
\text { - CRITERION: Fuel design parameters and features are established. }\end{array}$ \\
\hline 5 & & $\begin{array}{l}\text { - Samples using stockpile materials and separated materials are fabricated } \\
\text { at laboratory-scale using a representative process. } \\
\text { - Irradiation testing of small-samples (rodlets) are performed in prototypic } \\
\text { environment. } \\
\text { - Irradiation testing of pins is performed in relevant environment. } \\
\text { - Transient testing of fresh and irradiated samples and rodlets to establish } \\
\text { failure mechanisms is performed. } \\
\text { - Major models developed and tested; and performance code completed. } \\
\text { - CRITERION: Fabrication process parameters are defined. }\end{array}$ \\
\hline 6 & 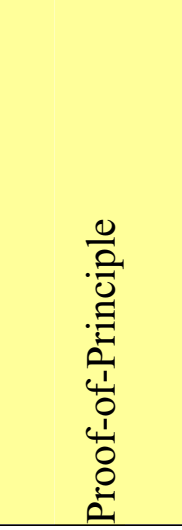 & $\begin{array}{l}\text { - Pins using separated materials are fabricated at laboratory-scale using a } \\
\text { prototypic process. } \\
\text { - Irradiation testing of pins is performed in prototypic environment. } \\
\text { - Transient testing of fresh and irradiated pins is performed to establish } \\
\text { DBA behavior and failure thresholds. } \\
\text { - Performance code verified and validated. } \\
\text { - CRITERION: Fuel design and process parameters and features are } \\
\text { verified and fuel safety basis is established. Lead test assemblies (LTAs) } \\
\text { are qualified for irradiation. }\end{array}$ \\
\hline
\end{tabular}


Table 4. (continued).

\begin{tabular}{|c|c|c|}
\hline TRL & Function & Definition \\
\hline 7 & \multirow{3}{*}{ 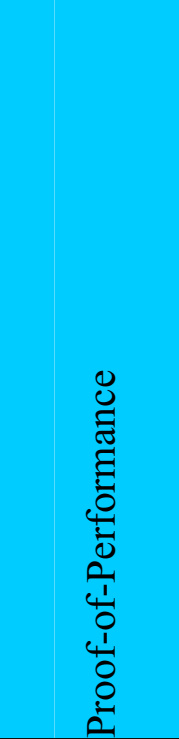 } & $\begin{array}{l}\text { - Test assemblies using prototypic feedstock materials at } \\
\text { engineering-scale are fabricated using prototypic fabrication process. } \\
\text { - Assembly-scale irradiation testing at prototypic environment is } \\
\text { performed (LTAs). } \\
\text { - CRITERION: Fuel qualification process is completed and reactor safety } \\
\text { basis is established for full-core operations. Fuel is licensed. }\end{array}$ \\
\hline \multirow[t]{2}{*}{8} & & $\begin{array}{l}\text { A few core loads of fuels are fabricated using a commercial-scale } \\
\text { facility. } \\
\text { CRITERION: Reactors are operated using the new fuel for a few } \\
\text { residence cycles. }\end{array}$ \\
\hline & & $\begin{array}{l}\text { CRITERION: Multiple years of operational experience established for a } \\
\text { commercial fabrication plant and routine operations of commercial } \\
\text { reactors for multiple cycles. }\end{array}$ \\
\hline
\end{tabular}

